\title{
Estado y nación durante el golpe contra Hugo Chávez
}

\section{Fernando Coronil}

Harvard University /University of Michigan ${ }^{1}$

Este ensayo tiene dos objetivos. En primer lugar, es una discusión sobre el golpe de Estado contra Hugo Chávez que se desarrolló entre el 11 y el 14 de abril de 2002. Se enfoca en las contrapuestas visiones de la oposición y de los partidarios del gobierno en relación con tres procesos: la marcha en protesta contra la violación de la meritocracia petrolera, la masacre del 11 de abril y el acto de proclamación de Pedro Carmona como presidente el 12 de abril. Examina en particular la coreografia de estos eventos y la transformación de las concepciones de la nación y el Estado involucradas en estos procesos. En segundo lugar, sobre la base de esta examinación, el ensayo concluye con algunas observaciones teóricas sobre el Estado, su constitución y la forma como ejerce su hegemonía.

Palabras Clave: Chávez, Venezuela, golpe de Estado, nación, hegemonía, ideología, imperialismo, petróleo, pueblo, encantamiento, fetichismo.

This essay has two objetives. In the first place, it is a discussion of the development

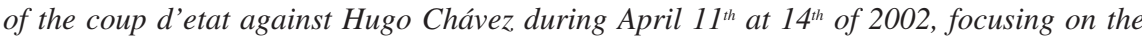
competing views of the opposition and supporters of the government in relation to three processes: the march against the violation of "meritocracia" in the oil industry (corporate criteria for selecting the managers of the state's oil company), the massacre that took place on April $11^{\text {th }}$, and the act of proclamation of Pedro Carmona as president on April 12 $2^{\text {th }}$. The essay examines in particular the choreography of these events and the changing conceptions of the nation and the state involved in these processes. Secondly, on the basis of this examination, the essay concludes with some theoretical observations concerning the state, its constitution, and the manner in which it exerts its hegemony.

KeYwords: Chávez, Venezuela, coup d’etat, nation, hegemony, ideology, imperialism, oil, people, enchantment, fetishism.

1 Escribí este ensayo durante mi estadía en la Universidad de Harvard como Fellow del Centro David Rockefeller de Estudios Latinoamericanos y profesor invitado del Departmento de Historia, donde estoy trabajando en un libro sobre el golpe contra Chávez. Por permitirme ausentarme durante este año estoy agradecido a la Universidad de Michigan, donde doy clases en los Departamentos de Antropoloía e Historia y dirijo el Centro de Estudios Latinoamericanos. Mis sinceros agradecimientos a mis colegas y amigos de Harvard por las valiosas discusiones que se encuentran reflejadas en este trabajo, a Silvia Álvarez y June Erlick, además, por sus numerosas sugerencias estilísticas, a Elio Gasparí, por sus iluminadoras comparaciones con Brasil, a José Falconi, por provocaciones sin fin pero con sentido, y muy especialmente a mis estudiantes del seminario sobre Venezuela quienes me enseñaron más de lo que puedo expresar aquí. 
Un fantasma recorre un continente pleno de encantamientos: el desencanto con el capitalismo. Apenas iniciándose, el tercer milenio nos da sorpresas: la historia no se presenta como la anunciaban (quienes tienen poder de hacerlo). Justo cuando la confrontación entre el socialismo y el capitalismo parecía un asunto del pasado y el libre mercado centelleaba en el horizonte como el reino del progreso, ahora su promesa de bienestar universal se revela, inclusive entre quienes más la enarbolaron, como un elusivo espejismo. Mientras que en los centros de poder metropolitanos se buscan ansiosamente correctivos al mercado que reduzcan la pobreza global imperante y aseguren su legítimo dominio, en América Latina, desde muchos sectores, se ve con más frecuencia al libre mercado no tanto como una neutra y eficiente solución tecnocrática para males colectivos, sino como un abultado remedio casero que si bien alivia algunos males, dispensa bienestar solamente a una minoría afortunada al costo de profundas heridas al cuerpo social y natural de la humanidad.

En un contexto global donde la economía capitalista formal ofrece posibilidades de logro y de lucro sólo a un fragmento de la humanidad, muchos buscan ahora contarse entre los afortunados que logran fortuna por medio del abuso del poder público. En la América Latina esto ha llevado a una intensificación de la duplicidad de un discurso político que con creciente frecuencia proclama la búsqueda del bien colectivo pero persigue el bien individual. La "corrupción" — palabra que condensa múltiples significados relacionados con violaciones de normas públicas en función del beneficio privado, desde la desidia en el trabajo, el clientelismo y las comisiones ilegales hasta el chantaje y el asesinato- se ha convertido en un fenómeno endémicamente estructural y culturalmente aceptado como parte de la cotidiana normalidad. Pero lejos de extinguirla, esta crisis económica y moral ha alimentado la esperanza de que alguien, o algo, ofrezca una solución que resuelva estas fracturas sociales y dobleces del alma y establezca un sentido de dignidad y comunidad.

\section{Nuevos encantamientos, viejos fantasmas}

Especialmente desde el "Sur," el supuesto advenimiento de un mundo definido por el "fín de la historia" anunciado por Fukuyama, o por "ideologías post-ideológicas" vislumbrado por Zizek, aparece como una fantasía de ciencia ficción sólo imaginable desde y para el "Norte." En una América Latina plena de memorias de luchas por la justicia, enriquecida por sus 
ideales y plagada de frustraciones, fragmentada por la pobreza y atravesada por profundas heterogeneidades sociales y culturales, el espectral desencanto con el capitalismo se transfigura cada vez con mayor frecuencia en el viejo fantasma del socialismo. Este moribundo espectro, tantas veces dado por desaparecido pero tantas otras reaparecido entre las grietas del capitalismo, aparece animando a los sectores radicales de muchos movimientos sociales desde la Patagonia hasta el Río Grande, sean éstos los piqueteros de la Argentina, los sin tierra de Brasil, los cocaleros de Bolivia o los zapatistas de México, así como impulsando las alas extremas de gobiernos progresistas, desde Kirchner y Lagos en el sur de la América Latina, Lula en el medio y el gobernador y aspirante presidencial López Obrador en su norte. Pero tal vez nadie como el presidente Hugo Chávez lo ha encarnado y reencantado con más espíritu, generando, según la mirada conque se lo mire, desbordadas esperanzas o desorbitados pánicos colectivos.

Mientras esto ocurre en el Sur, en el Norte el gobierno de George W. Bush ha convertido al terrorismo en el nuevo terror, transfigurando la llamada Guerra Fría en la Guerra contra el Terrorismo, una guerra infinita sin cuartel contra un enemigo al que no se le atribuyen fronteras, ideología, Estado, y casi ni siquiera humanidad. Contra esta malévola fuerza sin bordes, los Estados Unidos ha aparecido como un poder del bien obligado a desbordar los límites convencionales de la violencia en defensa de la humanidad. Y al asumir tan abiertamente el liderazgo mundial como defensor de la civilización, el republicanismo democrático de los Estados Unidos se ha revelado como el ropaje interior de una vestimenta imperial que crecientemente galardonea no ya sin disimulo sino con descarado orgullo. Desde el centro del imperio, ahora se lo critica no tanto por ser imperial, sino, como lo hace Niall Ferguson en Harvard, por no serlo suficientemente.

En medio de una guerra imperial contra el terrorismo, toda confrontación contra el imperio tiende a quedar cubierta, desde la perspectiva del imperio, bajo el manto de la lucha contra el terror. Como dijo el presidente Bush después del ataque del 11 de septiembre de 2001, el que no está con él en su lucha contra el terror, esta contra él. Y si el candidato presidencial Kerry, por oponerse a la guerra en Irak, fue reiteradamente presentado en los medios estadounidenses como un aliado de los terroristas, con igual sin razón ahora presentan a Chávez, dado su nacionalismo anti-imperialista, como parte del campo terrorista. Cuando en respuesta a la invasión decretada por Bush contra Afganistán Chávez mostró fotos de niños asesinados por las bombas estadounidenses y dijo que no se podía luchar el terrorismo con 
el terrorismo, Washington inmediatamente llamó a su embajadora en Venezuela para una reunión de emergencia para responder tal insolencia. En la guerra de palabras que se ha desatado, mientras más se acusa a Chávez de ser aliado de terroristas, o a los Estados Unidos de ser el mayor terrorista mundial, más se confirma el terrorismo como parte esencial de nuestra realidad, sea cierto o no lo que se le atribuye. Compartiendo temores, como si se reflejaran en espejos opuestos, los oponentes terminan pareciéndose y reproduciendo el discurso maniqueo que los separa y une a la vez.

En este contexto, si bien el capitalismo continúa dominando el panorama político como el único horizonte visible o viable para la humanidad, el luminoso futuro que anunciaba se presenta ahora oscurecido por esta guerra imperial infinita contra el terror y por proyecciones de persistente marginación, pobreza y destrucción ambiental en el mundo. Esta crisis social y discursiva ha ensombrecido especialmente a América Latina, la región con la más profunda desigualdad social en el mundo y a la vez con la más larga experiencia postcolonial y mayor cúmulo de búsquedas de los plenos beneficios de la modernidad. Esta yuxtaposición de esperanzas, temores y frustración la convierte en una zona particularmente susceptible de inestables apegos a políticos y políticas, a la volatilidad en las ilusiones, creencias y afectos, a súbitos encantamientos y penosos desencantos. Dentro de este ensombrecido paisaje, han encontrado fuerza movimientos y líderes que proclaman que otro futuro es posible.

Pienso que la polarización en Venezuela frente a Chávez debe verse dentro de la matriz de este clima mundial de discursos contrapuestos de factura maniquea. Para quienes confunden la incendiaria retórica de Chávez con sus menos fogosas acciones, su populismo anti-imperialista, unido a su solidaridad con Cuba, bastan para evocar el espectro de la implantación del socialismo en Venezuela. Como si estuviéramos en una caverna de terrores fantasmáticos made in Disneylandia, evidencia de la existencia real del socialismo no es realmente necesaria; su evocación espectral aterra con similar fuerza, como si la aparición de lo que se teme venir estuviera ya a cuerpo completo en el socialismo realmente inexistente venezolano; la democratización de la distribución de la renta petrolera (o al menos la ampliación de sus circuitos) es sin duda un cambio significativo, pero no puede confundirse con la socialización del capital, tanto en su forma de capital productivo y financiero, como de tierras rurales y propiedades urbanas. Precipitado en el presente, al futuro se lo ve en medio de signos que no se deben leer tal como figuran, sino como una prefiguración o disimulación. 
Como la duplicidad es parte de la naturaleza de este malévolo espectro que aparenta ser lo que no es para revelarse sólo cuando ya sea demasiado tarde, su presencia se manifiesta no por medio de signos transparentes, sino a través de claves opacas que exigen una traducción. La vida cotidiana venezolana se ha convertido en una decodificación permanente del espectáculo público: se practica diarianamente el arte de leer entre líneas, de ver detrás de la fachada, de identificar conspiraciones, de descubrir los disimulos del poder y las transfiguraciones de lo que aparece como la verdad. Para la oposición, el gobierno chavista encubre, bajo lo que presenta como una inmaculada vestimenta democrática, a un engendro totalitario o al menos autoritario. A pesar de las enormes diferencias con el proceso histórico que hizo posible el desarrollo del socialismo en Cuba, el espectro de Cuba pesa sobre la oposición como una pesadilla, en parte gracias a la presencia de una influyente colonia cubana que interpreta los pasos de Chávez bajo el prisma de las huellas, o heridas, que dejó Fidel Castro por su camino hacia el socialismo en la Cuba de los sesenta.

Sin que se dejen de reconocer algunas vinculaciones externas, la política en Venezuela se vive intensamente como un proceso estrictamente interno. Ubicándola como parte de esta crisis latinoamericana y mundial, en este ensayo la exploro como una crisis también de los discursos que la definen. Mi discusión se centra en las visiones polarizadas que han dividido a los venezolanos en dos bandos, dejando casi sin voz pública a quienes no se ubican en los extremos. ${ }^{2}$ Me enfoco aquí en los extraños sucesos del 11 al 14 de abril, cuando el presidente Hugo Chávez fue desalojado del poder por grupos apoyados en un sector de las Fuerzas Armadas después de una gigantesca marcha en protesta a su mandato, $\mathrm{y}$ fue devuelto al poder 48 horas más tarde, como resultado de fracturas entre la oposición y el apoyo de sus seguidores y defensores de la legitimidad constitucional.

Le seguiré la pista a tres hilos que ayudaron a tejer la densa urdimbre de esos días: la protesta contra la violación de la meritocracia petrolera, la representación de la masacre del Puente Llaguno y la proclamación de Pedro Carmona como presidente interino. Ubicaré esta discusión dentro del contexto de la cultura política venezolana, en la cual la nación se vive, según he argumentado en otros trabajos, como una entidad con dos cuer-

2 La polarización en dos bandos en Venezuela se ha alterado después del fallido intento de la oposición de revocar al presidente Chávez en el referendum del 15 de agosto; a partir de entonces, la oposición ha perdido apoyo y ha aumentado un sector intermedio, pero éste carece, hasta ahora, de representación pública. 
pos: un cuerpo material, formado fundamentalemente por el petróleo, y uno social, constituido por "el pueblo" o los ciudadanos como miembros de una comunidad, y se concibe al Estado como el ente que los protege y unifica. ${ }^{3}$ Al final, exploraré brevemente algunas ideas con respecto al Estado que tal vez permitan una mayor comprensión de los complejos procesos que establecen su hegemonía.

En ningún otro país ocurrieron en tan breve lapso cambios de gobierno tan súbitos y desconcertantes: nunca un presidente ha sido derrocado y devuelto al poder tan rápidamente y en medio de tan confusas circunstancias. Electo con el 56\% de los votos en 1998, la popularidad de Chávez había llegado al 80\% en 2001, pero para principios del 2002 se había reducido al 30\%. Este desencanto masivo vino unido a una intensificación y polarización de la lucha política en campos radicalmente opuestos. En un país acostumbrado a celebrar y afirmar la armonía social, a pesar de las agudas diferencias de ideología o de posición económica, la población se dividió enfurecidamente en dos bandos, cada uno más apasionado que el otro y convencido de poseer la única verdad. A tal punto llegó el desencanto entre los oponentes de Chávez, que partir del 2001, en gran parte gracias a su control de los medios, habían establecido como lugar común el hecho de que era imposible vivir en un país dominado por el chavismo. Convencida de que el país era un barco a la deriva comandado por un incompente capitán, la oposición se sentía obligada a deshacerse de Chávez por cualquier medio.

\section{El cuerpo natural de la nación ${ }^{4}$}

En medio de entrecruzadas conspiraciones y de un polarizado debate público caracterizado más por la intensidad de las pasiones que la claridad de las ideas, esta repolitización del país tuvo al menos la virtud de lanzar al debate público a sectores que nunca antes se habían movilizado por la polí-

3 Coronil, Fernando: El estado mágico. naturaleza, dinero y modernidad en Venezuela, Nueva Sociedad, Caracas, 2002.

4 Desarrollo el concepto del "cuerpo natural de la nación” en Coronil: El estado mágico... Basta decir aquí que baso este concepto en un amplio estudio del discurso político venezolano a lo largo del siglo XX y a nivel teórico lo apoyo en una integración del concepto marxista de renta del suelo, de las ideas de Lefebvre y Massey sobre el espacio y el tiempo, y del argumento de Kantorowicz sobre los dos cuerpos del rey. 
tica nacional. Politizados súbitamente, sin mayor contacto con los sectores que adversaban, muchos tomaban su realidad como la realidad. En este contexto de expectativas desmesuradas, el descontento de gente recientemente politizada cristalizó en la mayor marcha en la historia del país (hasta ese momento) para protestar, en principio la violación de la meritocracia petrolera, pero también con la esperanza de sacar a Chávez del poder. Chávez, haciendo uso de sus facultades legales, había despedido en forma airada (a través de su programa "Aló Presidente") a varios directivos de la compañía petrolera estatal, y nombrado otros que, aunque eran reconocidos expertos petroleros, saltaban los escalones habituales para la promoción a estas posiciones directivas. Una emotiva marcha de varios centenares de miles de personas (las cifras oscilan entre 300.000 y 1.000.000), autorizada para concentrarse en la "Plaza de la Meritocracia" frente a la sede de la compañía petrolera estatal PDVSA, fue prontamente desviada por sus dirigentes hacia Miraflores, el palacio presidencial.

Usando la violación de la meritocracia gerencial como bandera para aglutinar el rechazo de la oposición contra el gobierno, la marcha, que fue bautizada "Ní un paso atrás" para establecer su afinidad con otras luchas de significado histórico, radicalizó su consigna: desde tempranas horas de la mañana se pasó rápidamente de pedir la restitución de la meritocracia a exigir la renuncia de Chávez. La eufórica marcha ya no era para corregir una política del Estado, sino para conquistar al Estado. La extraordinaria magnitud de la marcha fomentaba la ilusión de que el país en pleno estaba con ellos y la historia en sus manos. Cantando consignas que marcaban otras luchas - "el pueblo unido jamás será vencido"- se creyó ese día que esa acción colectiva podría llevar al control del Estado, salvar al país de la deriva y cambiar el rumbo de la Historia. Como señala un artículo del periódico de la oposición El Nacional conmemorando la marcha del 11 de abril tres años más tarde, "el sentimiento de poder de esas masas humanas era total".

Aunque este cambio de consigna surgió desde los inicios de la marcha, sangrientos acontecimientos ocurridos en la tarde lo convirtieron en un clamor generalizado que le dieron mayor legitimidad y urgencia. En varios sitios alrededor de Miraflores, el palacio de gobierno, y del Puente Llaguno, sobre la avenidad Baralt, murieron baleadas 19 personas en situaciones bastante confusas. Inmediatamente, sin que hubiese evidencias claras, noticias televisivas de amplia divulgación por los canales privados acusaron al gobierno de causar estas muertes, repitiendo con insistencia la ima- 
gen de miembros y simpatizantes del gobierno disparando desde el Puente Llaguno contra "pacíficos manifestantes".

Aunque hay evidencias de que la rebelión militar (al menos la de algunos oficiales) venía planificada de antemano — que incluía posiblemente la propia masacre como su mecanismo justificatorio- a nivel público la "Masacre de Llaguno" o la "Masacre de Miraflores" rápidamente se convirtió en un detonante que transformó el repudio civil contra Chávez en una abierta rebelión militar. ${ }^{5}$ La repetida yuxtaposición de la imagen de representantes del gobierno disparando desde el Puente Llaguno y de cuerpos heridos o muertos de manifestantes pacíficos era exhibida por la televisión para demostrar la ilegitimidad absoluta del gobierno que asesinaba al "inocente pueblo." Se repetía por los medios que después de esta masacre se hacía intolerable un gobierno que había "ensangrentado sus manos con la sangre del pueblo," como proclamó ese día el veterano dirigente Luis Miquilena al distanciarse del gobierno que él había dirigido hasta entonces junto a su más avezado discípulo político, Hugo Chávez. Esa imagen fue mostrada en cuarteles a oficiales para establecer la legitimidad de la exigencia de la renuncia de Chávez. También circuló por los medios en los Estados Unidos y en países europeos y latinoamericanos, sirviendo de apoyo a declaraciones oficiales como las del gobierno de Bush a través de su jefe de prensa Ari Fleisher, quie apoyó al gobierno de Carmona al afirmar el 12 de abril que Chávez había provocado su propia caída por sus impropias acciones.

El 11 de abril, en un mismo día, el gobierno de Chávez era revelado a través de los medios televisivos e impresos controlados por la oposición como un usurpador de un Estado que hería gravemente tanto a la industria petrolera como al pueblo. Esta herida doble contra lo que yo he llamado "los dos cuerpos de la nación" - su cuerpo social y su cuerpo materialtambién hacía ilegítimo y hería mortalmente al Estado como representante de la nación en su unidad. En el imaginario político venezolano, formado en luchas democráticas contra gobiernos personalistas o sectarios que habían usado al rico Estado para su propio provecho, se da como un lugar común que el deber del Estado es establecer una armoniosa relación entre los ciudadanos y el territorio, entre pueblo y petróleo- entre los dos cuerpos de nación. Desde los tiempos del dictador Juan Vicente Gómez (1908-

5 De las evidencias que apoyan este argumento, este ensayo sólo menciona el video donde el vicealmirante Ramírez Pérez habla de seis muertes antes que éstas ocurrieran. En mi libro sobre el golpe discuto en detalle este complejo tema. 
1935), la nación había sido imaginada en Venezuela, por quienes se convirtieron en sus dirigentes políticos durante el siglo XX, como una entidad social y natural. Sólo podía representar legítimamente a la nación quien supiese proteger al pueblo asegurando que su riqueza colectiva - porque el petróleo es de todos los venezolanos- fuese usada para el bien común. Pero para lograr este objetivo se hace necesario también proteger al petróleo del asalto de los piratas del tesoro público que amenazan permanentemente con usarlo como botín individual. A partir de 1936, el Estado tomó forma como el protector de la nación encargado de dirigir la "siembra del petróleo," es decir, tutelar un proceso de transformación de la efímera riqueza minera en permanente valor social.

En abril de 2002, el discurso de la meritocracia petrolera fue usado como un escudo contra al temido espectro de un Estado que usaría el petróleo con fines sectarios y convertiría a PDVSA en una empresa tan ineficiente como muchas de las caóticas burocracias estatales. En un editorial de su periódico Tal Cual, el respetado líder socialista y periodista, Teodoro Petkoff, pedía apoyo a los petroleros que defendían la meritocracia en PDVSA enarbolando el argumento de su eficiencia: "En definitiva se está defendiendo que la empresa no se hunda en el pantano de la ineficiencia, que no se vuelva otro Seguro Social. No se les puede dejar solos" ( 8 de marzo, 2002). Dada la centralidad del petróleo en el imaginario nacional, a pesar de que se presentaba el argumento de la meritocracia como un asunto fundamentalmente gerencial, el reclamo de respetarla no era vivido sólamente como una violación de una normativa corporativa, sino como un mortal atentado contra las entrañas de la nación.

Por otra parte, desde la perspectiva del chavismo, el discurso de la meritocracia era una pantalla - una "mitocracia," como la llamaba repetidas veces Chávez- que escondía el interés de la oposición, apoyada por el gobierno de Bush, de cambiar el gobierno y controlar a la industria petrolera nacional. Según el gobierno, la nueva directiva estaba constituida por técnicos petroleros de reconocida y respetada trayectoria (cada uno con más de veinte años en la industria); sólo se habían saltado de cuatro a siete rangos en los méritos de los nuevos directores (en una escala de 1 a 36); en el pasado también habían ocurrido cambios parecidos sin que causaran protestas. El problema de fondo era de política, no de normas gerenciales. En efecto, el Estado chavista desde 1998 había cambiado el rumbo de PDVSA, pues según éste la compañía petrolera nacional, a partir de su nacionalización en 1976, se había convertido en "un Estado dentro de un 
Estado." La política del gobierno consistía en controlarla a través del ministerio del ejecutivo y por medio de una nueva directiva, fortalecer la OPEC, aumentar los precios petroleros a través de reducciones en la producción por medio de franjas de precios establecidas en el año 2000 por la OPEC (en gran parte gracias a la iniciativa de Venezuela), limitar la apertura petrolera hacia el capital extranjero y establecer leyes que aumentaban las regalías y el control estatal sobre inversiones en el sector enérgetico. Los opositores de Chávez estaban en contra no sólo del manejo gerencial que el Estado quería imprimirle a PDVSA, sino de su política petrolera. No apoyaban el subsidio petrolero a Cuba, ni la disminución de la producción de acuerdo con las cuotas de la OPEC y, en general, compartían la vision del ex-presidente de PDVSA, Luis Giusti, bajo el gobierno de Caldera según la cual a Venezuela le convenía ser una potencia petrolera a través de la maximización de la producción, y desligarse de la OPEC y sus restricciones. Desde la perspectiva del gobierno, la oposición interna encontraba apoyo externo, especialmente de los Estados Unidos que se enfrentaba al peligro de que Lula fuera electo en Brasil y a un inminente conflicto bélico en Irak. Ante la identificación de la energía y la seguridad en el reporte sobre energía dirigido por el vicepresidente Dick Chenney en mayo de 2001, era lógico pensar que los Estados Unidos apoyaría un cambio de gobierno en Venezuela que la asegurara como una potencia petrolera aliada a sus intereses.

Es curioso que en el debate público ocurrido durante estos tumultuosos días, ni el gobierno ni la oposición realmente centraran la discusión en los asuntos fundamentales de la política petrolera y de la geopolítica del petróleo. Por ejemplo, en los breves y acalorados discursos que dieron los dirigentes petroleros en la Plaza de la Meritocracia el 11 de abril en la mañana no se plantearon asuntos de fondo sino breves consignas dirigidas a motivar a los manifestantes. Y en el discurso que dio Chávez durante la tarde del 11 de abril tampoco aprovechó la oportunidad para explicar con cuidado los aspectos técnicos con respecto al problema de la meritocracia, la cual no mencionó como tal, ni los asuntos fundamentales de su política petrolera. Y esto sorprende porque el discurso público de Chávez, a pesar de mantenerse dentro de una retórica barroca dirigida a maravillar, se ha diferenciado por recurrir con frecuencia a la didáctica como género expositivo. Se actuaba en general como si se asumiera un consenso de entendimientos y sentimientos ya suficientemente asentados: el asunto era movilizarlos, no discutirlos o profundizarlos. 


\section{El cuerpo social de la nación}

El pabellón tricolor nacional, que durante la marcha hacia la Plaza de la Meritocracia en la mañana del 11 de abril había sido enarbolado por la oposición para protestar contra una política estatal pero que amparaba también el pedido de renuncia de Chávez, al final de la tarde era mostrado ensangrentado cubierto por los cuerpos de ciudadanos muertos para exigir, ya sin ningún otro amparo, su renuncia inmediata. Desde esa tarde, la imagen de las muertes de Llaguno asesinados por los "pistoleros chavistas" fue lanzada al aire por la televisión privada como prueba irrefutable de que se trataba de un gobierno que había perdido toda legitimidad. Como si hablara mil palabras con voz propia, pero acompañada de las palabras de locutores que parecían repetir un guión pre-fabricado, la repetición de la imagen del pueblo ensangretado por pistoleros chavistas reforzaba la insistente exigencia de la renuncia de Chávez.

Otra versión de estos eventos surgía de la perspectiva del chavismo, o inclusive de quienes fueron sus testigos. Quienes vieron lo que pasó en Puente Llaguno pudieron apreciar que los "pistoleros" no disparaban contra inocentes manifestantes, sino contra vehículos blindados de la Policía Metropolitana a cargo del alcalde Alfredo Peña, opositor de Chávez. Desde ese mismo día corrió el rumor generalizado de que la oposición había colocado francotiradores para matar personas en ambos bandos y justificar el golpe. Esta versión encontró apoyo en declaraciones posteriores de un periodista de CNN quie aseveró que el video del pronunciamiento en contra de Chávez de un grupo de altos oficiales leído por el vicealmirante Hector Ramírez Pérez que justificaba su insurgencia sobre la base de la muerte de seis manifestantes civiles había sido grabado antes que estas muertes ocurrieran. Al día siguiente, el 12 de abril, el vicealmirante fue designado Ministro de Defensa por Pedro Carmona. El juicio que consideró inocentes a los "pistoleros de Llaguno", así como los intentos posteriores para demostrar que el reportaje de Venevisión que mostraba la famosa imagen de la Masacre de Llaguno - y que ganó el prestigioso Premio Rey de España- era un montaje no parecen haber tenido mayor impacto en la opinión pública; o al menos entre los sectores de la oposición, tal vez porque los consideraban sesgados. ${ }^{6} \mathrm{~A}$ partir del

6 El documental "Claves de una masacre", dirigido por el cineasta Ángel Palacios, ofrece rigurosas evidencias que demuestran, al menos según lo que he podido investigar hasta ahora, que el documental de Venevisión es un montaje y que desde Puente Llaguno no se disparó contra la manifestación, sino contra los vehículos blindados de la Policía Metropolitana. 
11 de abril, para el grueso público venezolano que recibe información por medios televisivos, radiales e impresos controlados por la oposición, la versión que dominó ese día sigue aún vigente. Parecería que su memoria histórica, como si confirmara el hábito generalizado de un Estado de disimulo, se hubiese congelado en la potente imagen que encubrió a ese día.

En la tarde del 11 de abril, dos imagenes se juntaron en la visión de la oposición: el arremetido estatal contra el cuerpo natural de la nación, encarnado en el ataque contra PDVSA, y la violencia estatal contra su cuerpo social, encarnado en la masacre de manifestantes indefensos. Como he sugerido aquí, el significado de estos sucesos para uno y otro bando - las ideas, pasiones y sentimientos que evocaron- sólo se entiende al ubicarlos dentro del contexto de un complejo cultural que ha constituido al Estado en el guardián de la nación como entidad con doble cuerpo, natural y social. Pero los sucesos de abril hicieron evidente también cambios que este constructo de la nación, formado a lo largo del siglo XX, había sufrido hacia su final.

A partir de la crisis de los 80 el cuerpo social de la nación ya no podía ser imaginado como una armónica unidad, ni a su rico cuerpo natural como fuente de riqueza para todos, ni al Estado como el agente que lograría el milagro de una modernidad para el país. Ante la polarización social, el empobrecimiento de los sectores medios y populares y el endeudamiento del país, era difícil mantener ese mito. El evento emblemático de este cambio fue el "Caracazo" de 1989, cuando el Estado reprimió y causó la muerte de centenares de manifestantes que protestaban por la implementación de medidas de ajuste impuestas por el Fondo Monetario International. En contraste a las 19 muertes de abril de 2002, los 399 muertos de febrero de 1989 fueron aceptados por los medios y sectores que definen la "opinión pública", como el costo necesario para mantener el orden social y entrar a una etapa de austeridad y racionalidad definida por el mercado capitalista. ${ }^{7}$

Si bien los eventos de abril son la expresión de la fractura del cuerpo social de la nación, se los vivió desde posiciones extremas que la agudizaron aún más profundamente. Mientras para la oposición el Estado chavista había agredido a la nación en su unidad social y natural; para sus seguido-

7 Para una discusión detallada de estos eventos y de su representación pública ver Coronil, Fernando, Skurski, Julie: "Dismembering and Remembering the Nation: The Semantics of Political Violence in Venezuela", Comparative Studies in Society and History, 33, no. 2, 2001, págs. 288-337. La cifra de 399 muertos corresponde a los difuntos identificados por COFAVIC. La cifra official es 277. En medios periodísticos se especuló que hubo cientos de muertos más. 
res, Chávez la protegía contra un sector privilegiado que quería recuperar los beneficios que había disfrutado durante la IV República. Si el mito político de la IV República se apoyaba en la unidad de todo el pueblo representado por el Estado en aras de un proyecto modernizador capitalista, el de la V República chavista, reflejo de la polarización de un país empobrecido y sin horizonte claro de progreso colectivo, ofrecía la justicia para las mayorías en el contexto de una díficil modernidad en un mundo globalizado dominado por el imperialismo.

Un prisma producía visiones contrapuestas de los eventos del 11 de abril. Mientras que para la oposición Chávez transformaría a PDVSA en un apéndice de su grupo político, para sus seguidores PDVSA por fin iba a ser un instrumento al servicio del pueblo. Para la oposición las personas muertas del 11 de abril eran víctimas inocentes que revelaban la verdadera cara de un gobierno autoritario; para los chavistas, estas muertes, causadas por francotiradores de la oposición, eran la excusa para legitimar un golpe contra un gobierno popular.

Aun cuando estas dos versiones estaban en disputa, en la tarde del 11 de abril la balanza de poder se inclinaba hacia la oposición. A través de un despliegue masivo de los medios que controlaba, la masacre del 11 de abril sirvió para legitimar y exigir la renuncia de Chávez. A partir de la masacre, esta exigencia no venía no sólo de boca de civiles agrupados en la calle que protestaban contra la ilegitimidad de las políticas del Estado, sino de militares que desde sus cuarteles proclamaban la ilegitimidad del propio Estado. Si durante la marcha del 11 de abril los gritos de los manifestantes pidiendo la renuncia de Chávez no habían tenido suficiente fuerza de persuasión con respecto a Chávez, que se mantuvo sordo frente a este masivo reclamo público, a partir de la tarde del mismo día los pronunciamentos mesurados de los máximos oficiales de las cuatro armas de las Fuerzas Armadas iban fortalecidos por la persuasión de la fuerza: si Chávez no renunciaba, amenazaban con atacar al palacio presidencial.

Esta amenaza fue escuchada. Para evitar un baño de sangre, y siguiendo a sus consejeros domésticos e internacionales, Chávez aceptó que el general Lucas Rincón - su único general de tres soles con el más alto rango militar- anuncie su renuncia en la madrugada del 12 de abril pero tomando ciertos recaudos con respecto a su salida del país. Sin embargo, minutos después del anuncio, los militares en el cuartel Tiuna se opusieron a que Chávez se refugiara en Cuba, exigían que el presidente fuese enjuiciado en Venezuela por las muertes del día anterior. Ante este cambio en 
las condiciones acordadas, Chávez desistió en firmar el fax con el texto de la renuncia que le había sido enviado. Todavía para evitar la confrontación, Chávez aceptó entonces ser apresado pero no renunciar. Muchos vivieron ese momento como si Chávez hubiese realmente renunciado y el gobierno estuviese sin mando. Dentro de la confusión generada por esta situación, o al menos amparada bajo su justificación, la renuncia anunciada por el general Rincón ha servido hasta el día de hoy para alimentar la creencia, no sólo entre la oposición, que lo que ocurrió en Venezuela ese día fue un "vacío de poder".

\section{El estado de la nación}

En la madrugada del 12 de abril, con Chávez preso, con el vicepresidente Diosdado Cabello escondido, y con la Asamblea Nacional desbandada, el Estado chavista, tan concentrado en la figura de su presidente, se encontraba en efecto súbitamente descabezado. Ocupando su lugar sin más legitimidad que la ofrecida por el ejercicio del poder por quienes lograron ser reconocidos como sus agentes, un grupo de militares y civiles asumía funciones del Estado en el cuartel Tiuna. Tras los bastidores del escrutinio público, este pequeño grupo, evidentemente actuando sobre la base de planes pre-establecidos y con el aparente apoyo de altos dirigentes de las Fuerzas Armadas y de otros sectores claves del país, daba toques finales a los decretos y términos de la transición y confirmaba al líder empresarial Pedro Carmona como presidente interino. En un ambiente bastante caótico, en medio de apresuradas reuniones y consultas, Carmona, apoyado por sus seguidores, se ajustó a un plan original y rechazó el pedido que el presidente interino fuese designado por la Asamblea Nacional con los votos de una mayoría lograda por acuerdos politicos a última hora.

En el Salón Ayacucho del Palacio de Miraflores, al atardecer del 12 de abril, en una ceremonia que aspiraba ser espectacularmente histórica, Pedro Carmona se proclama presidente provisional en nombre de la leyes de la constitución de Chávez. En el mismo acto, nombra parte de un gabinete ejecutivo, elimina de golpe a los miembros de la Asamblea Nacional, a gobernadores y dirigentes municipales, todos electos en elecciones universales, y destituye al Tribunal Supremo de Justicia, al Fiscal General de la Nación y al Defensor del Pueblo. También anula las 49 leyes decretadas por Chávez en noviembre de 2001 bajo poderes especiales —las más con- 
troversiales eran la ley de tierras, que afectaba sobre todo a tierras ociosas, y la de hidrocarburos, que aumentaba la regalía y exigía mayoría accionaria estatal en empresas energéticas mixtas-, le devuelve el nombre de Venezuela a la República Bolivariana de Venezuela y suspende el acuerdo de suministrarle petróleo subsidiado a Cuba.

Esta ceremonia incluyó dos momentos emblématicos, aparentemente sencillos, que, sin embargo, evocaban en ese momento transcendental el imaginario de una nación herida y de su nuevo Estado protector. Para comunicar su deseo de sanar las heridas sufridas por el cuerpo social de la nación, Carmona inició sus palabras pidiendo un minuto de silencio en honor a los caídos el día anterior y ofreciendo ayuda a los familiares de las víctimas. ${ }^{8}$ Y para indicar su voluntad de salvaguardar al cuerpo natural de la nación, Carmona tomó especial cuidado en designar como presidente de PDVSA al general Guaicaipuro Lameda, un competente ingeniero que había mostrado estar de acuerdo con la visión corporativa de PDVSA dentro de la línea de su ex-presidente, Luis Giusti, ahora asesor de energía del presidente Bush. Para subrayar la importancia de esta designación, celebrada en círculos domésticos y extranjeros ligados al Estado y la industria estadounidense, basta decir que Carmona llamó al general Lameda a su casa a las seis y media de la mañana del viernes, justo después de ser confirmado como presidente por los oficiales en el cuartel Tiuna. Fue en cierta forma su primer acto de gobierno. En contraste, aún en la tarde del viernes durante su proclamación como presidente, Carmona nombró a ciertos ministros sin haberles avisado previamente y dejó para el futuro la designación de otros.

Para una eufórica oposición, la cadena de eventos que había apresado al país bajo el dominio de Chávez parecía romperse con este acto; el futuro mostraría que en realidad era sólo un eslabón más. Aparte del comprensible repudio que provocó entre quienes apoyaban a Chávez, la auto-proclamación de Carmona también produjo un intenso rechazo entre quienes querían liberarse de Chávez, pero no de ese modo. La crítica fundamental a nivel público era que Carmona había violentado las leyes al disolver poderes públicos, especialmente por destituir a los diputados de la Asamblea Nacional y a los gobenadores, todos representantes del pueblo

8 Sin quitar valor a este gesto, valga recordar que en 1989 ninguna organización empresarial o partido político protestó contra la masacre ocurrida contra centenares de venezolanos en manos del Ejército Nacional; COFAVIC, la ONG que se encargó de ayudar a las víctimas trabajó prácticamente a solas y en contra de la corriente. 
electos por medio de elecciones universales. Esta crítica iba acompañada por otra más privada pero no menos intensa: Carmona había establecido un gobierno elitista y sectario conformado por oficiales de la armada y personajes del partido COPEI, de la iglesia y del Opus Dei, que excluía a muchos de los sectores que trabajaron para derrocar a Chávez, incluyendo grupos del ejército, de la elite, de la clase media y de los trabajadores. Y pensando en su impacto general, se decía que después del gobierno de Chávez, el equipo de Carmona lucía "demasiado blanco". Como le exigió a Carmona en privado la noche del 12 un destacado miembro de la Iglesia: "Pedro, tienes que poner un negro ahí".

Es común que un golpe produzca un estado de excepción que violenta el orden legal en nombre de la ley. En este caso, la intensa defensa de la legalidad en medio de una situación de emergencia que necesariamente la violaba - o al menos que hacía evidente que la legimitidad podía ser sustentada de acuerdo con criterios contrapuestos- obliga a la reflexión. Este fuerte apego a la constitución podría verse como expresión de un genuino respeto hacia el orden legal y de un sincero deseo de defenderlo aun en el contexto de un Estado de excepción, o precisamente por tratarse de un regimen excepcional cuyos límites había que definir claramente desde el principio. Pero por otra parte, dado tanto el flexible cumplimiento de la letra de la ley desde los tiempos de la colonia como el fácil acomodo a su violación durante otros golpes de Estado en la historia reciente de Venezuela (por ejemplo, los golpes del 1945, 1948, 1952, y 1958) ${ }^{10}$ esta inflación del discurso legalista hace sospechar que en este caso jugaba un papel fundamental no sólo la violación de la ley, sino quienes la violaban y con cuáles fines, no sólo el poder de la ley, sino la ley del poder. Vinculando finamente ambos aspectos - las convenciones legales y las intimidades del poderTeodoro Petkoff mostró indignación frente a la auto-proclamación de Carmona en unas valientes declaraciones dadas por televisión en la misma tarde del 12 de abril en las cuales le aseguraba que se opondría a sus arbitrariedades así como lo había hecho contra las de Chávez. Su voz reflejaba un temor y un clamor colectivos.

En el teatro de Miraflores el 12 de abril, la representación del grupo que proclamaba ser el nuevo Estado no fue convincente no sólo por las fallas del script — la violación de las fórmulas legales — sino por fallas del casting

9 Entrevista confidencial.

10 Para una discusión de estos golpes y del doble discurso durante los mismos, ver Coronil: El estado mágico.. 
- la exclusión de actores influyentes. El drama no convenció tanto por su inepta representación de la legalidad, como por su falta de representatividad. Al caer el telón en el salón Ayacucho de Miraflores con las últimas palabras de Carmona, mientras un exclusivo público presente aprobaba con frenéticos aplausos el acto que terminaba, un público televidente mucho mayor observaba este aplauso como parte del acto mismo y a quienes aplaudían como el coro de una tragedia griega que anunciaba el significado profundo de la actuación en el podio principal. Este coro elitista, que un público mayor vio como un club de gente con vestidos "finos" y de "marca," o para los conocedores, con trajes Armani, corbatas Gucci, y camisas Zulka, y perfumados con fragancias Christian Dior o Hermés que, según me han dicho, "se podían oler a través de la pantalla," diseñadores del mundo al representar al exclusivo público del Estado de Carmona, revelaba su verdad: la gestación de un Estado elistista y excluyente detrás de una fachada democrática. Y como si confirmara su apariencia autoritaria, la persecución de chavistas en la calle engendraba el espectro de un gobierno represivo.

El problema no era solamente que el nuevo gobierno había violado la ley, sino que había concentrado el poder estatal en un grupo demasiado reducido, excluyendo no sólo a quienes se sentían con derecho a ser gobierno, sino a quienes tenían suficiente poder para respaldar esos sentimientos. La violación de la ley era emblemática de la violación de un pacto implícito de la oposición; la transgresión legal reflejaba una transgresión política. Estas transgresiones y los discursos que la expresaban se entrecruzaron íntimamente en la representación de estos eventos hasta que se confundieron. Tal vez sin la transgresión política, la transgresión legal hubiera sido aceptada, o tal vez ésta no hubiera podido ocurrir o no hubiera tomado la misma forma. En la contingencia histórica del momento, así como fue posible imaginar que Carmona hubiera podido proceder por la vía de la Asamblea Nacional, como le aconsejaron muchos, también se pudo imaginar que dentro de su mismo marco legal, Carmona hubiera includo a sectores más amplios — por ejemplo, nombrando como ministro de defensa al general del Ejército Efraín Vásquez Velasco, a representantes de los distintos partidos en el gabinete (especialmente Acción Democrática), y como vicepresidente a un representante de los trabajadores con piel oscura (como en efecto Carmona trató de hacer el sábado 13 de abril al proponerle esta posición al líder laboral de Acción Democrática, Manuel Cova). Si ya es difícil saber con certeza lo que sucedió en realidad en la historia, es imposible saber lo que hubiera podido suceder. 
Pero lo que sí se vivió en ese momento con la fuerza de una verdad absoluta fue el rechazo inmediato de amplios sectores al acto de Carmona. En vez de cambiar el rumbo del país y entrar en la Historia como su Salvador, se sintió que Carmona había provocado el decarrilamiento de la oposición. Comentando posteriormente estos eventos, agudos observadores como Carlos Blanco han argumentado que el golpe de Estado no ocurrió el 11 de abril contra Chávez, pues entonces la movilización popular en su contra provocó su salida del poder (en estas interpretaciones juega un papel muy importante la noción que Chávez había renunciado), sino el 12 de abril contra la oposición, al tomar Carmona el poder para sí. Otros comentaristas, como la revista Newsweek, presentaron la toma de posesión del poder de Carmona, más acertadamente a mi juicio, como "un secuestro del golpe," o como "un golpe dentro del golpe".

Frente a este repudio y al apoyo que Chávez recibió de partidiarios que habían tomado las calles, altos personeros del ejército, comandados por el general Efraín Vásquez Velasco (cuyo apoyo a Carmona se había entibiado por pensar que por rango y por arma le habría correspondido a él ser designado Ministro de Defensa), obligaron a Pedro Carmona a rectificar. Carmona convocó a la Asamblea Nacional en la tarde del sábado 12 para que sea ésta la que elija al presidente provisional. Como solución, esta propuesta era perfectamente lógica: aparte de ofrecer el manto de legalidad, también obligaba a la inclusión de diversos grupos y a la negociación política; el poder sería repartido y no exclusivo. Pero su rectificación no sólo se ajustaba al proverbio "demasiado poco y demasiado tarde", sino que también resultaba demasiado descarada. Carmona no sólo convocó a la Asamblea Nacional después de haberla disuelto de un plumazo el viernes 11 de abril, sino después de haber escapado de Miraflores al Fuerte Tiuna en la tarde del 13 de abril porque fuerzas chavistas empezaban a tomarlo. Ya el juego de fuerzas había cambiado.

En efecto, este tardío gesto de supuesta amplitud por quienes se proclamaron dueños exclusivos del poder el viernes 12 se interpretó el sábado 13 no como evidencia de una rectificación o de la magnanimidad de su mando, sino como señal de su debilidad. Visto como un acto desesperado para mantenerse en el Estado sin contar con su poder y su fuerza, este acto sólo encontró por respuesta la movilización en su contra de casi todas las fuerzas, inclusive de aquellas que lo habían apoyado y que ahora se prestaban a repudiarlo y convertirlo en el chivo expiatorio de un plan gestado en común por muchas manos. 
En el Palacio de Miraflores, la Guardia Presidencial, que sorprendentemente no había sido cambiada por los insurgentes y aparentaba apoyar o servir a Carmona, terminaba de tomar el palacio presidencial y de apresar a los miembros del gabinete de Carmona que se encontraban allí para juramentarse y que no habían logrado escapar. Y como en un replay invertido de lo que había ocurrido en la madrugada del viernes 12 , cuando los oficiales insurgentes amenazaron a Chávez de atacar a Miraflores si no renunciaba, ahora los oficiales que apoyaban a Chávez, por boca del General Baduel, comandante del cuartel de paracaidistas de la ciudad cercana de Maracay, amenazaban con bombardear a los insurgentes si no apoyaban la constitucionalidad.

Pero a diferencia de los partidarios que apoyaron a Chávez, las fuerzas de la oposición se plegaron rápidamente. Las calles, que había tomado tan masiva y dramáticamente el 11 de abril, a partir del 12 de abril sólo contaron con la presencia creciente de seguidores de Chávez. Y en contraste con los militares que apoyaron a la constitucionalidad, que habían logrado asegurar la lealtad de los oficiales medios que controlaban las tropas, los altos oficiales que insurgieron contra Chávez, sin mando real sobre los soldados, no tuvieron más recurso que rendirse, huir o ser apresados.

Al final de la confusa tarde del sábado, la Asamblea Nacional finalmente hizo su aparición, pero ya no para legitimar a Carmona, como él había propuesto bajo presión de las cambiantes circunstancias, sino para mostrar la vigencia de la Constitución y el retorno al poder del gobierno chavista. Después de haber recobrado la televisión del Estado, en otra dramática escenificación del poder estatal que tenía a los televidentes como su único público, la noche del sábado 13 de abril, los televidentes pudieron observar la juramentación como presidente de Diosdado Cabello, vicepresidente de Venezuela, a cargo de William Lara, presidente de la Asamblea Nacional. En realidad, sin embargo, la Asamblea Nacional no se había reunido porque no podía hacerlo en esas condiciones. Las cámaras sólo presentaron la imagen de estos dos líderes. En este otro teatro del poder, se afirmaba un principio legítimo de la constitución por medio de un acto de simulación.

Pocas horas después, a las cuatro de la madrugada del domingo 14 de abril, la televisora presentaba el retorno de Hugo Chávez al palacio presidencial, rodeado de una emocionada multitud, donde era reconocido como el presidente que nunca había dejado de ser. En medio de tanta confusión, entre la noche del sabado 13 de abril y la madrugada del domingo, Vene- 
zuela tuvo, o aparentó tener, tres presidentes: Pedro Carmona, Diosdado Cabello, y Hugo Chávez.

En esta cadena de confusiones, cada eslabón no era realmente resuelto, sino que era suplantado por otro que establecía el orden por ser el último, no por ofrecer un esclarecimiento general. La cadena de sucesos del 11 al 14 de abril se ha presentado de acuerdo con muchos guiones: una rebelión civil, si se enfatiza la gran marcha contra Chávez del 11; un golpe de Carmona contra el gran movimiento contra Chávez del 11 de abril, si se enfatiza el carácter exclusivo de su breve regimen y se da por cierta la renuncia de Chávez; un golpe cívico-militar, si se privilegia el apresamiento de Chávez y la proclamación de Pedro Carmona como presidente en desconocimiento de la legitimidad de la constitución; un "vacío de poder," si se toma al pie de la letra el anuncio de la renuncia de Chávez pronunciado por el General Lucas Rincón (esta posición fue asumida por el Tribunal Supremo de Justicia, el cual decretó el 14 de agosto de 2002 que no era golpe sino "vacío de poder"); un autogolpe dado por Chávez para descubrir a sus enemigos, si se cree que tuvo la maquiavélica habilidad de aparentar estar perdido para descubrir a sus enemigos; varios golpes no sincronizados, si se piensa que en un país tan mal organizado como Venezuela hubo muchos grupos conspirando y ninguno logró coordinar los acontecimientos; un "secuestro del golpe", o un "golpe dentro del golpe", si se ve al equipo de Carmona como un sector conservador, ligado al Opus Dei y a sectores financieros de derecha, que dio la espalda a sus conspiradores aliados y trató de conquistar el poder para sí; o como un golpe imperial organizado o con la participación de uno o más de los siguientes gobiernos y sus principales agencias de inteligencia: Bush (CIA, NSA, entre otras), Sharon (Mossad), Blair (MI6) y Aznar (CESID), si se privilegia la geopolítica del petróleo y la agencia de los centros metropolitanos, cuyos intereses convergían en garantizar el suministro de petróleo a los Estados Unidos, debilitar la OPEC, evitar un embargo petrolero contra Israel, defender las inversiones españolas en Venezuela y fortalecer la alianza entre los Estados Unidos, Israel, Inglaterra y España. En realidad estas versiones, o variantes de ellas, pueden ser complementarias. Tal vez porque ha sido difícil demostrar lo que realmente pasó, independientemente de que existan o no pruebas de su veracidad y que mezclen lo fantasioso con lo demostrable y plausible, las distintas versiones han sido mantenidas con encendido convencimiento hasta el presente. 
Para el momento en que escribo este ensayo - marcando ya el tercer aniversario del 11 de abril de 2002- las versiones contrapuestas todavía cubren los controversiales eventos de abril, sin mayor reconciliación o resolución. Nuevos escándalos tienden a tapar a los viejos y a dificultar que surja una verdad más persuasiva; intentos de resolverlos son interpretados como maniobras para beneficiar a ciertos sectores o perseguir fines ocultos. La masacre del 11 sigue sin solución legal o sin crónica definitiva, a pesar de, o a causa de, la existencia de reportes opuestos — así como siguen en el mayor y vergonzoso silencio las numerosas muertes que ocurrieron el 12 y el 13 de abril durante los saqueos y confrontaciones. Un ampliado Tribunal Supremo de Justicia, cuya legitimidad ha sido cuestionada por incluir doce nuevos magistrados, ha cuestionado la sentencia que determinó que los eventos de abril no constituyeron un golpe de Estado sino un "vacío de poder", por lo cual se ha abierto de nuevo el caso. Pero en estas palabras finales no quiero resumir nuevos hallazgos ni resolver anteriores debates, sino más bien explorar brevemente, sobre la base de la discusión que he presentado, algunas ideas sobre el Estado, que tal vez puedan ayudar a refinar nuestra comprensión de su forma y la manera como ejerce su hegemonía.

\section{Estado y hegemonía ${ }^{11}$}

Es fácil reconocer que un golpe de Estado es un hecho extraordinario. Sin embargo, me interesa verlo también en relación a lo ordinario, no sólo porque un golpe también está formado por una serie de hechos cotidianos, sino porque, como conjunto, forma una fase cuya intensidad excepcional le otorga características propias que hacen más visible los principios y relaciones que organizan la vida cotidiana. En este sentido la ruptura del orden ordinario durante un golpe se asemeja a la fase "liminal" o intermedia de los rituales discutidos por Arnold Van Gennep ${ }^{12}$ y Victor Turner ${ }^{13}$. De acuerdo con ellos, el período liminal de los ritos corresponde al proceso de transición entre la salida del orden habitual, y el reingreso a ese orden una vez sufridos los cambios impuestos durante la transición, como ocurre, por

11 Esta sección elabora ideas que he desarrollado en otros trabajos, especialmente en Coronil: El estado mágico...

12 Van Gennep, Arnold: Rites of Passage, The University of Chicago Press, Chicago, 1960.

13 Turner, Victor W.: The Forest of Symbols: Aspects of Ndembu Ritual, Cornell University Press, Ithaca, 1967. 
ejemplo, en los rituales de curación o de cambio de status social o personal. En los periodos liminales disminuye la normativa social convencional y se incrementan las representaciones culturales; los actores aparecen sin los atributos de sus roles tradicionales, como personas desnudas y sin ataduras (como naked unaccomodated man, en la feliz expresión de Turner) mientras adquieren los nuevos atributos, como por ejemplo la salud o el nuevo status de la adultez o la jefatura del grupo. Durante esta fase, las normas y valores sociales son a la vez cuestionados y afirmados, en una especie de carnaval metafísico y sensual que subvierte y agiganta los principios axiomáticos para hacerlos más visibles y reforzar, al final, al orden imperante.

Procesos similares ocurren también durante los golpes de Estado, pero sin la probable certidumbre de un resultado final pre-establecido, y con la carga tremenda de tener que re-estructurar un orden social desde los centros de poder. Esta obligación a re-establecer un orden desde la cima del Estado también los diferencia de lo que ocurre en los movimientos milenarios en sociedades complejas, cuya misión es establecer un orden distinto al margen de la sociedad, tal como muestra Victor Turner en su discusión del "proceso ritual". Durante el limen de un golpe de Estado, la ruptura con el orden normal se presta no sólo a la revelación y afirmación de los elementos axiomáticos del orden social, sino también a su redefinición o transformación. Por ello este tipo de orden liminal tiende a prestarse a la confusión de principios y normas, al cambio brusco de identidades, a dobleces y mutaciones de posiciones y lealtades, a la acentuación de contradicciones generalmente encubiertas, a la revelación de lo oculto y a la redefinición de las relaciones de poder. En ritos cíclicos, el orden establecido controla al desorden liminal; en golpes de Estado, el desordenado período liminal busca establecer un nuevo orden. En un golpe exitoso, el desorden liminal impone un nuevo orden; en un golpe fallido, el orden establecido se impone sobre el intento de reordenarlo. Pero aún en este caso, su reordenamiento implica necesariamente cambios; nada puede seguir igual que antes.

En los momentos liminales de un golpe de Estado, éste aparece desnudo y se muesrta como es en realidad: no sólo una encarnación del orden, sino también su creador. Como creador de sí mismo que aparenta no ser su propio creador sino el agente de un poder general, el Estado aparece en muchos sitios y por medio de muchos agentes: su encarnación varía de acuerdo con el lugar y al ente que defina y represente su poder. El Estado es la fábrica del Estado. Su ley puede aparecer como arbitraria o legítima, sus 
agentes como sus representantes o como impostores, su apariencia como de justa forma o falso artificio, las lealtades de sus sujetos como sólidas o mutables; sus variadas objetivaciones cambiando de forma al vaivén de los ritmos del poder. Durante un golpe, desde fuera o desde alguna parte del mismo Estado, otro Estado se proclama como legítimo. Si la actuación del nuevo Estado es efectiva, puede lograr desplazar al viejo; si no lo es, los aspirantes a representarlo se convierten en sus ilegítimos usurpadores.

Durante el golpe en Venezuela, Pedro Carmona pasó rápidamente de ser aclamado por los medios como un gran estadista, en su breve momento de gloria, a no ser más que "Pedro el Breve", como lo llamarían después de caído, jocosa pero también despectivamente, quienes lo alababan cuando ocupaba el poder. El contraste fue aún más extremo con respecto a la representación pública de Chávez durante estas cambiantes horas, quien pasó rápidamente de ser despreciado públicamente en los vergonzosos términos reservados para las conversaciones íntímas de los sectores más racistas y clasistas de la oposición, a ser alabado como un presidente cuyos extraordinarios atributos no podían seguir siendo despreciados; de un "mono" que no sabía hablar ni gesticular, pasó a ser un "brillante orador," envidiable "encantador de serpientes," y "sagaz político".

El Estado, como encarnación de la nación, se objetiva a través de múltiples discursos y prácticas que proclaman representarlo; el "efecto Estado" se logra a través de la efectividad de estas objetivaciones. El Estado es así el conjunto de relaciones y objetivaciones particulares que lo constituyen como el agente general de la nación. Como forma general, su compleja identidad se forma desde posiciones que reflejan y constituyen toda una cartografía del poder: palacio presidencial, ministerios, oficiales, cuarteles, burocracias, personalidades, discursos, leyes, códigos, ceremonias, actos. Si se sabe hacerlo bien y se tiene el poder de hacerlo, el Estado puede ser representado o redefinido desde cualquier agencia, posición o individualidad particular, sean multitudes desde la calle, militares desde un cuartel, líderes políticos desde la televisión o un empresario desde el palacio presidencial. Pero los momentos liminares de un golpe de Estado revelan que esta cartografía del poder estatal, dibujada por múltiples manos, se esculpe no sólo sobre un majestuoso mármol, sino sobre la humilde arena, cuyos trazos pueden demarcar formas tan permanentes como una estatua, pero también tan efímeras como líneas dibujadas sobre minúsculos cristales.

El Estado nacional es su propio fetiche y el de la nación; su mistificadora forma de representarla y de representarse es parte esencial de su cons- 
titución como su representante. Desde esta perspectiva, el Estado no es, como afirmara Philip Abrams, la "máscara" que encubre al sistema políti$\mathrm{co}^{14}$, ni el sistema político detrás de la máscara, sino la unión mistificadora de la máscara y lo enmascarado, lo visible y lo oculto. Su invisibilidad, sus secretos son parte esencial de su ser; su mayor secreto es su invisibilidad a pesar de su materialización permanente. Lo que he llamado la "forma Estado," de modo similar a la forma mercancia pero por medio de un abanico más amplio de corporizaciones, funciona por medio de relaciones sociales objetivadas en múltiples particularidades —instituciones, discursos, objetos, emblemas, individuos, espacios - las cuales no son entidades meramente independientes con atributos propios, ni sólo símbolos, sino los medios a través de los cuales el Estado se constituye y adquiere significado como una forma general. Al igual que la forma mercancia, la forma Estado no sólo se encarna o simboliza por medio de objetivaciones particulares, sino que se realiza mediante ellas. Como tal, el Estado se forma a través de objetivaciones que establecen una relación de equivalencia entre lo concreto y lo abstracto, lo particular y lo general —una equivalencia simbólica que permite que objetivaciones individuales aparezcan como el Estado sin que este pueda ser reducido a ninguna de ellas.

Si Chávez había logrado aparecer como la encarnación del Estado, la oposición trató de romper ese vínculo entre su persona y el Estado, presentándolo como el agente responsable de la masacre del 11 de abril. Para que el ejército pudiera forzarlo a abandonar el palacio Miraflores, había primero que desalojarlo de un Miraflores simbólico, romper el encanto que lo convertía en un ícono de la nación, reducirlo a un ser común, aún más: a un usurpador del verdadero poder. Lo primero que hicieron los militares cuando llegó preso al Cuartel Tiuna fue despojarlo de su vestimenta militar y ponerle un vulgar mono para ejercicios atléticos ("un mono para el mono" como comentó alguien). Igualmente, el acto de proclamación de Carmona, a pesar de todo el esfuerzo que desplegó en estructurar su coreografía, no logró objetivar la forma general del Estado sino hacer evidente su parcialidad - los intereses particulares que organizaron este simulacro del poder estatal. Pero esto revela también, como señaló una vez José Ignacio Cabrujas, el dramaturgo venezolano y brillante observador de nuestra cultura política, que el Estado venezolano se constituye a través de actos de

14 Abrams, Philip: "Notes on the Difficulty of Studying the State", Journal of Historical Sociology, 1988, pág. 32. 
disimulo. Yo agregaría que todo Estado se constituye por medio de distintas formas de simulación; el secreto del Estado es hacerla invisible.

Es evidente que durante los golpes de Estado afloran acalorados conflictos entre grupos contrapuestos: el Estado encarna razones y pasiones. Su capacidad de persuadir y dominar el espacio cultural y político — su hegemonía - involucra el control sobre los sujetos en su integridad corporal y espiritual, no sólo el poder sobre sus ideas e intereses, sino sobre sus posiciones y disposiciones espirituales y corporales en el cuerpo social. Quiero destacar dos aspectos sobre el concepto de hegemonía. En primer lugar, el concepto de hegemonía se refiere a un orden permanentemente construido y disputado. No creo útil identificarlo con el dominio de lo habitual en contraste a la ideología como el terreno de lo consciente ${ }^{15}$; si fuésemos a aceptar esta distinción, el concepto de ideología hegemónica demuestra precisamente la imposibilidad de separar las prácticas habituales de las actuaciones conscientes en sus cambiantes relaciones. En segundo lugar, esta unión entre lo habitual y lo conciente subraya que la hegemonía involucra tanto la construcción y mantenimiento del consenso alrededor de intereses e ideas compartidos entre clases opuestas, del "sentido común" tan central en la noción de hegemonía gramseiana, como un sentir común que se realiza por medio de la comunión de los sentidos. Esta integración de factores cognitivos y emotivos, del juicio y la fe, se traduce en la formación de posiciones y disposiciones corporales y espirituales tanto individuales como colectivas.

Siguiendo una larga tradición de escenificaciones espectaculares de la política en Venezuela, los eventos públicos que he analizado aquí fueron también con frecuencia fábricas del Estado para producirlo o reproducirlo. Como escenarios para mostrar la presencia del Estado —ocultando los artificios de su construcción y haciendo del disimulo un modo genuino y legítimo de ser-, buscaban no sólo convencer por la fuerza de la razón, sino también arrastrar por el flujo emotivo de la retórica y de la acción. Durante estos tumultuosos días, actos como la marcha "Ni un paso atrás" que avanzó de la Plaza de la Meritocracia a Miraflores, la representación mediática de la "Masacre de Llaguno" o la proclamación de Carmona en el Salón Ayacucho del palacio presidencial, lograban sus efectos no tanto por medio de iluminaciones, sino a través de deslumbramientos. En medio del drama

15 Comaroff, Jean; John Comaroff: Christianity, Colonialism, and Consciousness in South Africa, vol. 1 of Revelation and Revolution, University of Chicago Press, Chicago, 1991. 
del momento, los guiones públicos que orquestaban estos actos creaban "estados de encantamiento": complejos de ideas y sentimientos que seducían —o repugnaban - a los sujetos por su impacto sensorial total, no sólo por la lógica ordenada de ideas o razones. Como en posesiones rituales, se desplegaban fórmulas convencionales para invocar un vasto repertorio de ideas y sentimientos encarnados en lo profundo de cada ser.

Así, en días forjados por dramáticas acciones orientadas a cambiar o defender el rumbo de la Historia de acuerdo con visiones en pugna, donde se enfrentaron y confundieron lo digno con lo abominable, lo genuino con el disimulo, se daba una vez más la común y tantas veces dolorosa paradoja que nos obliga a reconocer que los seres humanos hacemos nuestra historia, pero en medio de las condiciones que nos forman y que la impulsan detrás de nuestras espaldas. Como si fueran partos de la Historia, los momentos liminares de un golpe de Estado nos hacen sentir su fuerza y nos constituyen a la vez como una comunidad y como individuos, capaces de llevar a cabo inusitadas acciones individuales y colectivas, y de fundir nuestros cuerpos, nuestras vidas, con los de la nación. Tal vez un entendimiento más profundo de estas condiciones nos ayude a comprender cómo tanta gente pudo actuar con tanta fe en su capacidad de hacer que la historia siga el camino de sus visiones, y al final, una serie de contingencias llevaran a resultados inesperados que sorprendieron a los mismos que la impulsaron. 